\title{
Detailed study of AI/ML in Smart Agriculture
}

\section{Anshika Agarwal $^{1}$, Y. D. S. Arya ${ }^{2}$, Gaurav Agarwal ${ }^{3}$, Shruti Agarwal ${ }^{4}$}

${ }^{1} \mathrm{Ph} . \mathrm{D}$. Scholar, Department of CSE, Invertis University, Bareilly, India

${ }^{2}$ Professor, Department of CSE, Invertis University, Bareilly, India

${ }^{3}$ Assistant Professor, Department of CSE, Invertis University, Bareilly, India

${ }^{4}$ Assistant Professor, Department of CSE, SRMSCET, Bareilly, India

\begin{abstract}
Article Info

Volume7, Issue 3

Page Number: 130-145

Publication Issue :

May-June-2021

\section{Article History}

Accepted :10May 2021

Published :15May 2021

This work explores the tools and technologies used in smart agriculture. Artificial Intelligence and Machine Learning techniques, including basic block models that are used to do smart agriculture. How can we use fuzzy logic and Artificial Neural Network, is also covered in this paper. We have explored some of the IOT based irrigation systems including crop prediction systems. The necessary hardware, software and sensors that can be used to make precision agriculture are also included. The main motto of this paper is to get a detailed literature review that is required for smart agriculture.

Keywords : Artificial Intelligence, Machine Learning, fuzzy logic, Artificial Neural Network, IOT, Precision Farming
\end{abstract}

\section{INTRODUCTION}

METHODS THAT ARE USED FOR AGRICULTURAL WORK traditionally ARE NOT much effective and convenient. It REQUIRES a lot of workforces and regular monitoring. So, to REDUCE the labor and increase productivity, we need to switch TO smart agriculture over traditional farming methods.

A farmer in traditional methods of agriculture needs to focus on the parameters such as soil moisture, temperature monitoring, humidity, etc. So obviously labor cost is more and continuous monitoring is not possible all the time.

We can use the Internet of Things to minimize the cost. IOT is the integration of various things like sensors, network objects, and devices that we use to automate data recording. By using IOT tools we can suggest actions required.

Artificial Intelligence has also been widely used in many fields, be it medical science, education, finance, agriculture, industry, security, etc. AI trains machines so that they can take decisions in the same way humans take.

Machine learning is the subdomain of AI. The main task involved in the process of machine learning is that we put the data in the machine that has come from past results and this data, is used by the machine to make further decisions. In fields like voice recognition, image identification, weather forecasting, etc, trained data is analyzed. 
ML is a mathematical approach to build intelligent machines. With the advancements in $\mathrm{AI}$, various other ideas and methods were invented and discovered which simplified the problem-solving task. Few methods are:

1. Fuzzy logic

2. Artificial neural networks (ANN)

3. Neuro-fuzzy logic

4. Expert systems

\section{Literature Review}

A lot of things have been developed in the field of AI over the last many years because of its soundness in the application and since it is ubiquitous in almost every field. An example of it is agriculture which we have explored in this paper. Agriculture is the backbone of India and it also faces a lot of challenges every day.

Factors that prevent the crop from developing are-

- Poor water availability

- Extreme temperature

- Competition among plants for sunlight, nutrients, water or space

- Uncontrolled use of chemicals

- Fungal, bacterial or viral infection

- Attack from insects or other organisms above or below ground

- So our objective is to-

- Automate monitoring and analysis task of farmers

- Identify plant disease

- Forecasting crops

- Detection of larva activities

- Monitoring intrusion of animal in fields

- Maximizing yield using minimal resources

2.1 Basic block models for smart agriculture

2.1.1An event driven WSN for monitoring plant health and Larva activiies [4]
- $\quad$ ARM Cortex A4 processor-based WSN for data collection (including Larva activities) from sensors has been used. This has been awakened by the base station.

- Sensing nodes transmit data only in case when there is much difference in values that is going to automatically reduce the power consumption.

- Extracted data from a group of sensing nodes is transmitted to the Base station by using wireless Zigbee protocol.

- The base station is connected to the CPU via USB Liaison between CPU and Base station, and here we can see all the collected data which we received from the sensors in the form of an ACI analysis and this analysis is done using Matlab.

2.1.2UAV Routing protocol for crop health management [20]

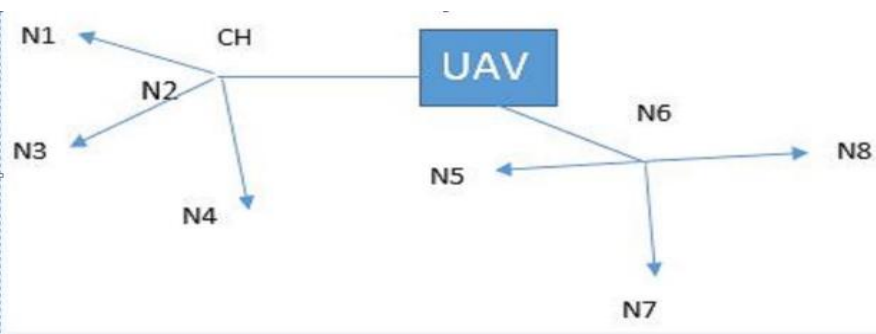

Fig 1. UAV routing protocol

- All sensors nodes are heterogeneous and can be different in size. Among these nodes, one node is chosen as a cluster head (CH).

- To select $\mathrm{CH}$, an algorithm is defined and the probability of each node participating in $\mathrm{CH}$ is calculated by the Bayesian classifier algorithm.

- All the member nodes deliver data to $\mathrm{CH}$ using TDMA (Time Division Multiple Access) scheme.

- $\mathrm{CH}$ will give data to UAV (unmanned aerial vehicle) (drone).

- Simulation is done in OMNET ++ and the path of a drone is given in advance. 
2.1.3Precision agriculture monitoring system using Green IOT[33]

a) Requirement analysis - all the functional and nonfunctional requirements are gathered.

b) Specification level - specify the required devices based on requirements gathered and only those sensors will get activated, this will saves cost automatically.

c) Architectural level - identify slave node and master node. All the slave nodes are responsible to provide the data to the corresponding master node.

d) Component level- its duty is to perform all the functions in architectural level.

Hardware components- devices and sensors

Software components- BBB debian, cloud9IDE for programming editing, debugging python code

e) Integration level- this level is responsible to connect all the components to form required architecture.

f) Application level- results will be displayed on the application.

\subsection{IOT based Irrigation System}

In 2014, GPRS feature of a mobile phone was used to develop an irrigation system by R. Suresh et al. In this microcontroller-based rain gun irrigation system, water supply will be there only when there is acute water shortage. The sole purpose is to save water, but this system is not financially affordable.

In 2017, ArifGori et al [5] suggested a system which uses mesh technology to place sensor nodes in agricultural areas. Base station (which is stationary) is responsible for collecting the data from these sensors (they are mobile). In the wake of gathering all the information base stations at that point procedure the information. $\mathrm{PH}$ sensors were utilized to check if the dirt was acidic or antacid in nature, the detected qualities from the $\mathrm{pH}$ sensor were sent to the android application and as needed choices were taken.

GA Gines et al [15] used fuzzy logic in 2017 to classify rice and maize soil moisture sensor readings in the categories "too wet," "wet," "normal," "warm" and "too warm." Such readings can be used to evaluate the threshold value for these two crops which can be used to turn the motor pump on / off. In 2018, Ms. Swapnali B. Pawar et al [19] used raspberry pi which was attached to 3 sensors, namely a soil moisture sensor, a temperature sensor and an ultrasonic sensor. To test the irrigation system the Wi-Fi is linked to this platform. In 2018, Ankit Verma [3] suggested another model i.e. "Crop monitoring in wireless sensor network". This model gives SMS facility to farmers which tells the farmers about the soil condition i.e. whether the soil is dry or wet. So that they can provide effective irrigation and control the water wastage.

In 2018, Shobha S. Kumbar et al [27] proposed a device that was divided into 3 sections-sensing part of humidity, section of control and section of production. Soil humidity is evaluated by using a YL69 sensor, and the control unit is the Arduino platform based ATMega328 microcontroller. The sensor sends the sensed data to the microcontroller, which then works by flipping the motor pump on and off accordingly.

\subsection{Fuzzy logic in smart agriculture}

Fuzzy operators perform like a human driver and thus alter the interaction between input and output corresponding to previously defined series of membership functions and guidelines. A fuzzy skeleton is a linguistic-based control device, which tries to imitate a human expert's actions. Six inputs and two outputs appear in AgriSys [1]. They have used the multiple input to multiple-output ( MIMO) type using the fuzzy logic library under LabVIEW. This system is deployed on a web server to allow remote access and controlled or observed via any smart device.

- Five inputs with its specific minimum and maximum values are used in this system namely, humidity, temperature, $\mathrm{PH}$, soil moisture and thermocouple.

- Its function's specifications are as follows: 
- Rectangular Humidity membership function is regarded dry if its sensor value is less than 55 and wet if its sensor value is more than 50 .

- Trapezoidal $\mathrm{pH}$ membership function is considered in either of the categories; Acidic, Normal, and Alkaline.

- Triangular Environment Temperature membership function is categorized as Cold, Warm, and Hot.

- Triangular Soil Temperature membership function is considered as Cold, Warm, and Hot.

- Trapezoidal Soil Moisture (water level) membership function is considered as Unsaturated and Saturated.

For siphon and the fan, the output membership functions are triangular, which oversees its $\mathrm{ON}$ or OFF status. The machine screen depends on the light just, and it closes during the daytime and opens around evening time. The derivation framework which was created depends on 25 principles. An example is suppose when the temperature is hot, humidity is wet, $\mathrm{PH}$ is alkaline, soil moisture is saturated, and soil temperature is hot; at that point the siphon is OFF with a switched ON fan.

The framework has a simple to-update bank of derivation rules to manage the farming condition. This project, for the most part, takes a gander at inputs, for example, temperature, stickiness, and $\mathrm{pH}$. Also, the framework manages desert-explicit difficulties, for example, dust, barren sandy soil, steady twist, exceptionally low stickiness, and the extraordinary varieties in diurnal and occasional temperatures. The framework gives expanded efficiency, improved security, moment mediations, and a propelled way of life.

\subsection{Artificial neural networks in agriculture}

ANN strategy was developed by remembering a similar idea of the working of the human cerebrum. ANN is an undertaking-based strategy which advises the framework to work dependent on some inbuilt errand instead of a regular computational modified assignment. The engineering of ANN comprises of 3 layers:

\section{Input layer \\ 2 Hidden (middle) layer \\ 3 Output layer}

ANN model comprises numerous neurons, each delivering a grouping of genuine esteemed activations. At the point when sensors see condition varies, initial neurons will be actuated and different neurons will at that point get initiated through weights associations from already active neurons. Contingent upon particular issues and the topology used, these practices may need some computational work, where every one of the stages changes total actuation of the system. Deep learning permits computational models that are made out of different handling layers to speak to information with various degrees of reflection. Incredible enhancements of the strategy have been visible in many examination areas. The idea of Back Propagation Neural Network is the reason for some DL calculations. With enormous eagerness filling the DL field, extraordinary upgrades have been accomplished lately. DL has attracted a great deal of consideration for horticulture. One of its applications in agribusiness is picture acknowledgment, which has vanquished a ton of hindrances that break point quick improvement in mechanical and automated agro-industry and farming. These upgrades have been seen in numerous parts of agribusiness, for example, plant infection recognition, weed control, and plant checking.

So as to give a comprehensive image of DL to scientists in agribusiness fields and upgrade present day shrewd farming turn of events, this work sums up BP and normal DL calculations (Convolutional Neural Networks (CNN), Recurrent Neural Networks 
(RNN), and Generative Adversarial Networks (GAN)) and their applications in horticulture, with attention on applications distributed over the most recent years. Song (2005) [29] united expert system and ANN in forecasting the nourishment level in the yield. The entire framework is based on a solitary chip PC.

Second, COTFLEX framework for the cotton was created by Stone and Toman (1989) [32]. The framework was designed as a shot at Pyramid 90× PC with UNIX as a working framework. The framework consolidated the field and homestead databases to give significant data in regards to the cotton yield to the rancher with the goal that it turns out to be simple for the cultivator to make basic and strategic choices. The framework was created in Texas, and it made recreation models and DB in the standard based master framework to enable Texan ranchers to make judicious financial and rewarding choices. After testing COTFLEX was imported to IBM microcomputer and was made open for use.

A specialist framework PRITHVI by Prakash et al. [7] (2013) dependent on fuzzy and implemented on Matlab was created in Rajasthan, India for Soybeans crop. It accumulates its information from rural officers, distributed writing, specialists of soybean crops. Fuzzy rules were considered in contemplating the entire framework and exhorting the rancher as a specialist. This system was separated into 5 modules. The primary point of building up this master framework was to aid the ranchers in the enhancement of production.

In 2016, a forecasting technique that recommends the utilization of ANN calculations for crop forecasting in smart phones had been effectively tried [24]. This framework had 3 layers. The efficiency of the model was reliant on the quantity of the concealed layers. The experimentation strategy was executed to pick the no. of shrouded layers. This can be a précised approach to investigate the choice of shrouded layers because the expectation framework's precision is subject to the quantity of concealed layers. It was also observed that if we want a more precise forecast than we should increase the no. of shrouded layers.

A report in India that evaluates the significance of the expansion of ANN in a few methods of approximation of ET. Specialists assembled month to month atmosphere information for it. The techniques on which the calculations were performed were: 1 . Penman-Monteith strategy 2. Levenberg-Marquardt backpropagation. It was seen that expanding the quantity of concealed layers in the framework brought about unsteadiness in the ET estimation. Along these lines, preparing capacity with an ideal experimentation technique is to be picked for the general advanced estimation of ET. It was seen that out of 6 preparing calculations of the ANN model, work preparing with $74 \%$ information provided in it was exact. ANN model was planned and created utilizing MATLAB. 6 calculations were summoned and surveyed. As evapotranspiration is of imperative significance in the water system and water the executives, this examination showed the prescient procedure of ANN structure whenever actualized accurately [23].

Moreover, a technique was made to segregate weeds from crops with the assistance of picture investigation and neural systems having precision of over $75 \%$ with no already plant data taken care of into the framework. Shahzadi et al. (2016) [2] created master frameworks based shrewd horticulture framework. The idea of IoT in this framework was to provide information to the server with the goal that actuators of the field ought to have the option to make proper choices. For that, the server ought to be sufficiently smart to make choices freely. 
2.4.1Convolutional Neural Network in smart agriculture

Plant sickness discovery is tedious when it is done physically. Luckily, with the advancement of manmade consciousness, plant sickness recognition can be cultivated through IP. Plant infection acknowledgment systems are the most dependent on leaf image classification and pattern recognition [37]. An epic DL structure was utilized to construct a plant disease identification structure. This structure can perceive 13 unique sorts of plant illnesses, with the capacity to recognize plant leaves from their environmental factors. In an examination of utilizing Deep Learning in the location of plant ailments, the general precision may arrive at $95.7 \%$ after 100 preparing emphasis and might be improved to $96.4 \%$ after further tweaking. The outcomes are in reality superior to manual location. All these demonstrated that DL has noteworthy execution in recognizing plant maladies.

AlexNet [36] which is used for plant classification is actually a pretrained convolutional neural network. Results of this model in 2017 propose that the CNN engineering beats AI calculations that depend on available created highlights for the segregation of phenological stages. One more investigation, selfarranging Kohonen maps (SOMs) were utilized for optical image segmentation and resulting in rebuilding of lost information in a period arrangement of satellite symbolism. This strategy included a post-preparing step that incorporated a few sifting calculations dependent on the accessible data and geospatial investigation. A precision of $84.9 \%$ was accomplished for characterization of significant harvests [28]. In any case, there are difficulties that have hindered the utilization of $\mathrm{CNN}$ for plant grouping.

Organic product checking is significant for yield forecasting. The customary manual tallying or portable camera checking can't give acceptable outcomes and are tedious. A blob detection technique has been demonstrated to be helpful [10], which has suggested to go with a fully CNN. The underlying advance of the structure is to assemble manmadecreated names from a lot of organic product pictures. At that point, this method fully convolutional network (FCN) was prepared to perform picture division. From that point, the check convolutional organizer was prepared to take the segmented picture and output the estimation of the number of fruits. Our last goal is to map the number of fruits counted initially with the final number of fruits counted manually by training a linear regression equation. This methodology utilizing Deep Learning with blob detection improved the exactness as well as the productivity of checking.

Satellites, UAV are not generally utilized to research different assets [17] dependent on deep CNN (DCNN) and transfer learning (DTCLE). A characteristic identification technique dependent on DCNN had been utilized to find out cultivated land data. Lastly, this extracted information were ended by the DTCLE and e-Cognition for cultivated land information extraction (ECLE). The general accuracy of both are around $90 \%$, yet as far as integrity and continuity is concerned, DTCLE beat ECLE. The use of UAVs grants securing high resolution pictures.

To find out any object i.e. detection of any item is a quickly developing domain in Deep Learning. In the horticulture area, detection is additionally significant for ranchers, particularly when exceptionally selfruling machines have been progressively utilized. So as to work these tools securely but not to oversight, these machines should be highly reliable with automatic real time risk detection [12]. A system with accuracy of $99.8 \%$ in crops and $90.7 \%$ in grass is there when image classification is done with AlexNet and DCNN. It has improved the performance also and is also far better than traditional methods[31].

2.4.2 Recurrent Neural Network in smart agriculture 
Recurrent Neural Network (RNN) is extremely valuable for time arrangement information and also utilized in numerous rural zones.

Classification of plants based on its characteristics is now a very fervently discussed issue, but also troublesome, since its need for precision agriculture is growing day by day. Rapidly, plant phenotyping expects to see a plant through its appearance or characteristics. Another DL structure for classification of categories of plants affirmation was made [21], here CNN and LSTM units both are obtained simultaneously.

Additionally, CNN, RNN techniques are widely used for forecasting of crops that also use information on time arrangements to minimise bias. In paper [18], authors have proposed 2 RNN-based classifiers, the LSTM network and the Gated Recurrent Unit (GRU) network, and used them. In addition to monotemporal models, to mapping the quality of winter vegetation. Their results showed that for a 5-overlap cross-approval dataset, the GRU model outflanked every other model, with a precision of 99.05 percent.

LAI i.e. leaf area index is a main property of various horticulture skeletons. LAI is basically used in order to find out the weather condition, forecasting of crops and carbon cycle etc. Exact LAI along with its elements are mainly used for condition, vegetation status and carbon cycle estimations, and so on. Conventional techniques for estimating LAI comes under 2 classes: experimental methods and physical techniques. Its results may experience the ill effects of transient discontinuities. A model based on RNN i.e. NARX (Nonlinear Autoregressive model process with exogenous input) has been applied to address the issue. This model had previously taken autonomous contributions to thinking as well as the yield of the model, making it all the more remarkable and [9] set up a model dependent on the NARX model called NARXNN to assess LAI time-setting.
Here authors have prepared the system on a few datasets and conducted circuitous and direct approval, the 2 of which proposed that NARXNN would be a reliable device in order to estimate LAI time series. In paper [11], authors used a NARX model to anticipate rubber LAI in application.

Recurrent Neural Network is helpful for time arrangement, which was along these lines utilized in climate gauging. Three models for climate forecast were analyzed in [8]: a RNN-based model called NARXnet, a case-based reasoning model (CBR), and a segmented CBR model. This structure implies NARXnet had the option to gain from authentic information as well as from past forecasts. The NARXnet has a 93.95 percent exactness, altogether outflanking the other two models. Furthermore, authors of [38] set up another LSTM model to anticipate a city's climate qualities of 24 and 72 hours: temperature, dampness, and wind speed. They utilized 15-year information from hourly ascribes to prepare the model and acquired serious outcomes contrasted and other customary strategies.

Soil moisture is an urgent hydrological trait for horticultural precision, and environmental change. $\mathrm{SM}$ in horticulture, in any case, is a component of numerous variables, also it can shift incredibly with reality, causing trouble in precise estimation. Neural systems are clearly pertinent to this job, as they can inexact complex capacities and criticism from time arrangement. Authors of [22] tried a simplified NARX model with just the current highlights input and the expectation it had given in the last step of the time. Direct validation showed that both frozen and unfrozen seasons kept their model steady and serious. Moreover authors of paper [13] utilized a standard NARX model to evaluate soil moisture elements. They utilized a NARX model (DLNN as they called it) to hourly anticipate soil moisture, and contrasted the forecasts with ground estimations. The outcomes 
indicated the model was a decent instrument for the mission.

RNN was also used on both the macroscopic and microcosmic scales to study animals. RNN-based systems have proved to be highly competitive with the advancement of deep learning. The movement of elephant herds in South Africa is hurting the endangered vegetation species. Authors of paper. [16] Trained an RNN system in combination with an algorithm for particle swarm optimization to forecast the positions of the herds of elephants. The outcomes demonstrated that the RNN system could convey a low degree of blunder forecasts. One more investigation, authors of paper [6] applied a firstorder RNN for pig development estimation. The outcome indicated that the first-order RNN worked superbly in anticipating pig development.

\subsubsection{Generative Adversarial Network in smart agriculture}

Generative Adversarial Network is another type of neural system however has been viewed as a helpful strategy in numerous fields, particularly in the processing of pictures. Generative Adversarial Network was generally used to grow the datasets. It wasn't generally applied to horticulture.

GAN was utilized by Ledig et al. [35] to determine loss of highlight brought about by down testing. At the point when an image is compressed, a few highlights might be lost or gotten off base and photograph sensible surfaces should be recouped from it. To do as such, they presented a perceptible loss function consisting of an antagonistic misfortune and lost contents. The content loss function they utilized was roused by perceptual likeness when contrasted with generally utilized pixel-wise MSE loss. Having been prepared with $350 \mathrm{~K}$ pictures, their model had the option to recuperate profoundly impacted pictures. This examination is imperative to such an extent that it very well may be remembered for practically any project that includes image processing. This examination is principal to the point that it very well may be utilized in image processing projects, especially in farming where numerous applications depend on remote detecting pictures.

In another investigation, [26] endeavored to defeat the hole between the requirement for a lot of data DL models and the absence of physically commented on datasets. To improve the authenticity of synthetic farming pictures. In their work, they utilized 10,500.0 synthetic, 50.0 empirically annotated, and 225.0 unlabeled observational pictures to prepare their model and guessed that the comparability between engineered pictures and exact pictures could be improved subjectively to improve the interpretation of highlights. The outcomes indicated that the synthetic images were very much deciphered on nearby highlights, for example, shading, scattering of enlightenment and surface while interpretation of worldwide highlights was not very great.

\subsection{Crop Prediction System}

In March 2018 Vrushal Milan Dolas and Prof. Uday Joshi [35] aimed to use a decision tree algorithm to characterise soil based on its nutrient content. Also predicted crops which are suitable for specific soil types. Two decision trees algorithms that are widely used are Classification and Regression Trees (CART), and C4.5. The big downside of the CART is that it makes errors when the selected parameter area is more while the C4.5 algorithm is partial towards more value attributes. In order to overcome these disadvantages, they proposed a modified approach to the decision tree. Instead of calculating for each pair as per the CART algorithm, they first computed the gini index for various sets of parameter values, and then used ratios of these measured gini indices to minimize the bias brought about by knowledge gain in C4.5 algorithm. 
In August of 2011, authors of paper [26] used decision tree induction to study the impact of climate attributes on soybean productivity to assist researchers and farmers in pre-analyzing market dynamics. For the period 1984-2003, agro-climatic data was collected from Bhopal district. Year, rainfall, evaporation, temperature, and relative humidity were the attributes used. A decision tree for soybean crop yield was constructed taking relative humidity as the root node.

Table 1. Crop prediction systems with advantages and disadvantages

\begin{tabular}{|c|c|c|c|c|c|}
\hline $\begin{array}{l}\text { S.n } \\
\text { o. }\end{array}$ & $\begin{array}{l}\text { Author/ Research } \\
\text { Paper Reference }\end{array}$ & $\begin{array}{c}\text { Techniques } \\
\text { used }\end{array}$ & Parameters & $\begin{array}{c}\text { Advantage/ } \\
\text { Disadvantage }\end{array}$ & Result \\
\hline 1. & $\begin{array}{l}\text { ArifGori, } \\
\text { Mangleshet al [5] }\end{array}$ & $\begin{array}{l}\text { Arduino } \\
\text { microcontroll } \\
\text { er and GPRS } \\
\text { module }\end{array}$ & $\begin{array}{l}\text { Soil moisture, } \\
\text { soil pH, light } \\
\text { intensity }\end{array}$ & $\begin{array}{lr}\text { cost effective } & \text { for } \\
\text { optimizing } & \text { water } \\
\text { resources } & \text { for } \\
\text { agricultural } & \\
\text { production } & \end{array}$ & $\begin{array}{l}\text { Through this } \\
\text { project it can be } \\
\text { concluded that } \\
\text { there can be } \\
\text { considerable } \\
\text { development in } \\
\text { irrigation with } \\
\text { those of IOT and } \\
\text { automation. }\end{array}$ \\
\hline 2. & $\begin{array}{ll}\text { Ms.Swapnali } & \text { B. } \\
\text { Pawar et al [19] } & \end{array}$ & Raspberry pi & $\begin{array}{l}\text { Temperature } \\
\text { and humidity }\end{array}$ & $\begin{array}{l}\text { This project uses } \\
\text { raspberry pi and } \\
\text { defines it as the heart } \\
\text { of the system. Use of } \\
\text { raspberry pi improves } \\
\text { power consumption } \\
\text { and results in } \\
\text { increased } \\
\text { conductivity }\end{array}$ & $\begin{array}{l}\text { The system } \\
\text { effectively } \\
\text { controlled the } \\
\text { activities of plant } \\
\text { growth. }\end{array}$ \\
\hline 3. & $\begin{array}{l}\text { Ankit Kumar et al } \\
{[3]}\end{array}$ & $\begin{array}{l}\text { Zigbee } \\
\text { technology is } \\
\text { used for } \\
\text { communicatio } \\
\text { n between the } \\
\text { network } \\
\text { elements, it } \\
\text { provides less } \\
\text { power }\end{array}$ & $\begin{array}{l}\text { Soil moisture, } \\
\text { humidity,ligh } \\
\text { t and } \\
\text { temperature }\end{array}$ & $\begin{array}{l}\text { This system reduces } \\
\text { water wastage and } \\
\text { results in optimized } \\
\text { consumption of } \\
\text { energy }\end{array}$ & $\begin{array}{l}\text { Reduces manual } \\
\text { effort and the need } \\
\text { to constantly } \\
\text { monitor the field. }\end{array}$ \\
\hline
\end{tabular}




\begin{tabular}{|c|c|c|c|c|c|}
\hline & & $\begin{array}{l}\text { consumption } \\
\text { and hence was } \\
\text { preferred over } \\
\text { other } \\
\text { technologies }\end{array}$ & & & \\
\hline 4. & $\begin{array}{l}\text { SrishtiRawal et al } \\
\{30]\end{array}$ & $\begin{array}{l}\text { GSM module } \\
\text { and } \\
\text { arduinouno }\end{array}$ & Soil moisture & $\begin{array}{l}\text { Reduced water } \\
\text { wastage and effective } \\
\text { watering to crops. }\end{array}$ & $\begin{array}{l}\text { Automation of } \\
\text { sprinkler system } \\
\text { helps } \\
\text { monitoring water } \\
\text { supply to field. }\end{array}$ \\
\hline 5. & $\begin{array}{l}\text { V. VinothKumar et } \\
\text { al [34] }\end{array}$ & $\begin{array}{l}\text { Arduino was } \\
\text { used as the } \\
\text { microcontroll } \\
\text { er and } \\
\text { ESP8266 for } \\
\text { real time } \\
\text { sending of } \\
\text { data to the } \\
\text { user }\end{array}$ & $\begin{array}{l}\text { soil } \\
\text { temperature, } \\
\text { Humidity, } \\
\text { value of } \\
\text { chlorophyll } \\
\text { of the crop } \\
\text { and height of } \\
\text { the crop }\end{array}$ & $\begin{array}{l}\text { Transmits real time } \\
\text { data to user }\end{array}$ & $\begin{array}{l}\text { This system aims } \\
\text { at providing } \\
\text { advancement in } \\
\text { irrigation system } \\
\text { and transmitting } \\
\text { the real time } \\
\text { condition of the } \\
\text { field. }\end{array}$ \\
\hline 6. & G A Gines et al [15] & $\begin{array}{l}\text { Arduino } \\
\text { microcontroll } \\
\text { er and GSM } \\
\text { Shield }\end{array}$ & Soil moisture & $\begin{array}{l}\text { Accurate data of soil } \\
\text { water level for rice } \\
\text { and maize. } \\
\text { Involvement of } \\
\text { farmer in both } \\
\text { turning on and off of } \\
\text { the motor pump }\end{array}$ & $\begin{array}{l}\text { Too Wet, Wet, } \\
\text { Normal, Dry, Too } \\
\text { Dry are the } \\
\text { categoriesin which } \\
\text { soil moisture } \\
\text { values r are } \\
\text { classified. }\end{array}$ \\
\hline 7. & $\begin{array}{l}\text { Dr. V. Balamurugan } \\
\text { et al [14] }\end{array}$ & $\begin{array}{l}\text { Arduino } \\
\text { UNO, XBEE } \\
\text { and UPS. }\end{array}$ & Temperature & $\begin{array}{llr}\text { System requires less } \\
\text { man power for } \\
\text { operation.System is } \\
\text { cost effective. }\end{array}$ & $\begin{array}{l}\text { Through this } \\
\text { system we can step } \\
\text { in to an unmanned } \\
\text { irrigation, which is } \\
\text { highly efficient. }\end{array}$ \\
\hline 8. & $\begin{array}{l}\text { S NaliniDurga et al } \\
{[25]}\end{array}$ & $\begin{array}{l}\text { Arduino } \\
\text { UNO, } \\
\text { Amplifier }\end{array}$ & Soil moisture & $\begin{array}{l}\text { Programming is done } \\
\text { on Arduino } \\
\text { microcontroller UNO } \\
\text { R3 in such a way that } \\
\text { it gives the interrupt }\end{array}$ & $\begin{array}{l}\text { If the moisture } \\
\text { level falls below a } \\
\text { threshold value, a }\end{array}$ \\
\hline
\end{tabular}




\begin{tabular}{|c|c|c|c|c|c|}
\hline & & Circuit & & $\begin{array}{l}\text { signals to the motor via } \\
\text { the motor driver } \\
\text { module. }\end{array}$ & $\begin{array}{l}\text { signal is sent to the } \\
\text { Arduino board } \\
\text { which turns the } \\
\text { Water Pump ON. }\end{array}$ \\
\hline 9. & $\begin{array}{l}\text { Shobha S. Kumbar } \\
\text { et al [27] }\end{array}$ & $\begin{array}{l}\text { Arduino was } \\
\text { used as the } \\
\text { microcontroll } \\
\text { er }\end{array}$ & $\begin{array}{l}\text { Temperature } \\
\text { and moisture }\end{array}$ & $\begin{array}{l}\text { The output sensor } \\
\text { value is compared } \\
\text { with the fixed value } \\
\text { in the comparator LM } \\
393 \text { and signal is } \\
\text { transmitted for } \\
\text { processing in } \\
\text { microcontroller }\end{array}$ & $\begin{array}{l}\text { Good vegetation of } \\
\text { crop is achieved by } \\
\text { using sensors with } \\
\text { proper threshold } \\
\text { values. }\end{array}$ \\
\hline 10. & $\begin{array}{l}\text { Vrushal Milan } \\
\text { Dolas et al [35] }\end{array}$ & $\begin{array}{l}\text { Classification } \\
\text { and } \\
\text { Regression } \\
\text { Trees } \\
\text { (CART), C4.5 } \\
\text { algorithm }\end{array}$ & $\begin{array}{l}\text { Soil } \\
\text { parameters } \\
\text { namely pH, } \\
\text { EC(Electrical } \\
\text { Conductivity) } \\
\text { and } \quad \text { ESP } \\
\text { (Exchangeabl } \\
\text { err Sodium } \\
\text { Percentage) }\end{array}$ & $\begin{array}{l}\text { Tracking down the } \\
\text { requirement of water } \\
\text { by the soil and } \\
\text { scheduling the } \\
\text { irrigation accordingly. }\end{array}$ & $\begin{array}{l}\text { Classified soil } \\
\text { based on its } \\
\text { nutrient content. } \\
\text { Also predicted the } \\
\text { most suitable crop } \\
\text { for particular soil } \\
\text { type. }\end{array}$ \\
\hline 11. & $\begin{array}{l}\text { S. Veenadhari et al } \\
{[26]}\end{array}$ & $\begin{array}{l}\text { ID3 } \\
\text { algorithm is } \\
\text { used }\end{array}$ & $\begin{array}{l}\text { Year, rainfall, } \\
\text { evaporation, } \\
\text { temperature } \\
\text { and relative } \\
\text { humidity. }\end{array}$ & & $\begin{array}{l}\text { Predicted the } \\
\text { productivity of } \\
\text { soybean in Bhopal } \\
\text { district. }\end{array}$ \\
\hline 12. & $\begin{array}{l}\text { S.Veenadhari et al } \\
{[26]}\end{array}$ & $\begin{array}{l}\text { C4.5 } \\
\text { algorithm. }\end{array}$ & $\begin{array}{l}\text { Rainfall, } \\
\text { temperature, } \\
\text { Potential } \\
\text { Evapotranspir } \\
\text { ation, Cloud } \\
\text { cover. }\end{array}$ & $\begin{array}{l}\text { Was developed for } \\
\text { selected crops that are } \\
\text { Soybean, Maize, } \\
\text { Paddy and Wheat. }\end{array}$ & $\begin{array}{l}\text { Developed a } \\
\text { website named } \\
\text { Crop Advisor' for } \\
\text { forecasting the } \\
\text { impact of climatic } \\
\text { factors on the crop } \\
\text { yields using C4.5 }\end{array}$ \\
\hline
\end{tabular}

\subsection{Hardwares}

\subsubsection{Arduino UNO}

It is a type of microcontroller board that is based on Atmega328 and produced by Arduino cc. Owing to its powerful on-board processing, sensors and other 
tools are integrated with the arduino. It contains six analog pins and fourteen digital pins. Used for

programming Arduino IDE. The voltage for service is 5 volts. Arduino UNO reads the values from the sensors and will instruct the driver to turn on / off the motor pump based on these values.

\subsubsection{ESP 8266Units}

ESP 8266 is a cost-effective, leading Internet of Things network. It is used to relay field real-time data over the IOT network. It has dual functionality, and a self-contained Wi-Fi networking solution can be used that can carry and drive the whole application. It can also be used to power other microcontroller units as a Wi-Fi adapter that can host more complex applications than ESP supports. Arduino UNO will be the primary microcontroller device in this project and ESP 8266 will serve as Wi-Fi adapter. The ESP 8266 has multiple general purpose I / O pins that are used to directly interface sensors to the Microcontroller. It is embedded with a 32-bit microcontroller that drives on board communication, power modes and the GPIO's. It works within 3.0 to 3.6 volt power range.

\subsubsection{Motor Driver}

Arduino UNO works at 5 volts but the engine takes 9 volts to run. The engine also needs a higher current than what the Arduino has to offer. We can use a controller circuit called the motor driver for this purpose. The motor driver circuit acts as an interface between the motor and the Arduino UNO. It provides the power needed for the motor to run.

\subsubsection{Raspberry Pi}

To help its speed, the Raspberry Pi 3 Model B expands on the highlights of its forerunners with another, quicker processor onboard. It additionally consolidates WiFi and low-vitality Bluetooth capacities to improve network and the capacity over USB ports to control increasingly cell phones.

Micro USB power source upgraded, up to 2.5A. The Raspberry $\mathrm{Pi}$ is a single board of computers developed to encourage and help programming and computing teaching. It is also a fantastic starting point for Internet of Things (IoT) projects in progress.

Pi's low cost and 'plug-and - play' design allows for a board that is open to all and has many networking options. $\mathrm{Pi}$ is the perfect experimental tool, whether you want it to be used in your home as a desktop, media center, server or monitoring / security device. No boundaries. Operating systems based on Linux run on the Pi with plenty of free software access.

\subsubsection{Relay}

A relay is a gadget which is operated electrically. Numerous relays utilize an electromagnet to precisely operate a switch, however other working standards, for example, strong state relays, are likewise utilized. Relays are utilized where a circuit must be constrained by a different low-power signal, or where a few circuits must be constrained by one signal. It is known as a contractor kind of transfer that can deal with the high force required to straightforwardly control an electric engine or different loads. Since relay are significantly more resistant to nuclear radiation than semiconductors, they are generally utilized in safety critical logic. Electromechanical protective relays are utilized through the opening and shutting of circuit breakers to distinguish over-burden and different flaws on electrical lines.

\subsection{Sensors}

\subsubsection{Temperature Sensor}

DHT-11 sensor is used to measure temperature and humidity. The ambient air temperature is measured 
by means of a thermistor. This system uses less power and is cost responsive.

DHT 22 is an IC temperature sensor with a temperature-proportional output (in ${ }^{\circ} \mathrm{C}$ ). The temperature is measured more accurately by the DHT 22 sensor than the thermostat. The range of operating temperatures ranges from $-40^{\circ} \mathrm{C}$ to $120^{\circ} \mathrm{C}$. The output voltage in response to each ${ }^{\circ} \mathrm{C}$ rise / fall in ambient temperature varies by $10 \mathrm{mV}$.

\subsubsection{Humidity Sensor}

YL-69 probes and sensors YL-38 are used for measuring the soil's moisture content. The YL-69 probes are composed of two copper strips, painted with epoch paint to improve conductivity. Aluminum is used to make one of the sensor samples, and the second sample is coated with polyaniline nanoparticles to enhance conductivity.

The humidity sensor is a small condenser produced by a dielectric material mounted between a pair of electrodes. Scope of calculation 0 - 100 per cent RH. Average sensing period: every two seconds. Current: 1.3 - $2.1 \mathrm{~mA}$. Size: 25.1 X 15.1X7.7 mm.

\subsubsection{Water Level Sensor}

The water level sensor parameters are 0utputs: 4.0$20.0 \mathrm{~mA}$ or 0.50 to $2.50 \mathrm{VDC}$, supply voltage: 3.30 to 5.0 VDC, dimensions: $60.0 \times 20.0 \mathrm{~mm}$, contacts 45.0 $\mathrm{mm}$, when the water level is low then the digital output is high and the sensitivity is adjustable.

\subsubsection{Data collection schemes from sensors}

Static sink routing

mobile sink direct contact data collection

Rendezvous based data collection

hash table-based routing

\subsection{Decision Trees}

Decision trees are ordinarily utilized for classification in data mining. A Decision tree is a flowchart like a tree structure where a test on a trait is indicated by an interior hub and the consequence of the test is connoted by each branch and the classes are spoken to by the leaf hub. The starting node is known as the root hub. An obscure example is arranged testing its attribute values along the decision tree and following a path from root node to a leaf node that holds the forecasting class label. Decision trees are of 2 types:

Classification tree: If the predicted output is a class name then the Decision tree is called as a characterization tree.

Regression tree: In the event that the predicted result is a real number, at that point the decision tree is called a regression tree.

\section{CONCLUSION}

Field monitoring is the obviously a required lessening people intercessions. Agribusiness observing is the very important factor on which we should focus as it helps with the decrease of work and augmentation of creation. Artificial Intelligence has been executed in choosing the best yield and to assist the ranchers in the decision of the composts. With the assistance of the database which the customer has aggregated and resolved to the structure, the machine talks about among themselves to pick which yield is sensible for gathering and moreover the composts which advance the greatest turn of events. DL has a wide reach and its application in the business has gotten an extraordinary progression. With the use of DL, it is an extra good situation over $\mathrm{AI}$ and it adds profundity to AI. This, at long last, helps the country in generally speaking advancement as food is the chief need of any person. IOT meant its monstrosity to help in the continuous perception of the data. IOT is 
fundamentally utilized in a smart watering framework. Since practical use of the open freshwater is significant, and with progress in development and utilization of innovation, the emergency identified with water can be tackled. Both water lack and flooding are the difficult issues farmers face by utilizing traditional methods.

In this paper, we have given a detailed literature review of factors that are concerned with smart agriculture. Techniques that are covered for artificial intelligence to sensors, hardware, or software that can be used for smart agriculture we have explored in this paper. This paper will help to get a detailed idea about the things related to machine learning in smart agriculture.

\section{REFERENCES}

[1]. Aalaa Abdullah, Shahad Al Enazi and Issam Damaj, "AgriSys: A Smart and Ubiquitous Controlled- Environment Agriculture System", 2016 3rd MEC International Conference on Big Data and Smart City, 978-1-4673-9584-7/16, IEEE.

[2]. Aitkenhead, M.J., Dalgetty, I.A., Mullins, C.E., McDonald, A.J.S., Strachan, N.J.C., 2003. Weed and crop discrimination using image analysis and artificial intelligence methods. Comput. Electron. Agric. 39 (3), 157-171.

[3]. Ankit Kumar Verma, Bhagavan.K, VamarajuAkhil, \& Amrita Singh (2018), Wireless network based smart irrigation system using IOT, International Journal of Engineering and technology.

[4]. Areej sabo, S.M. Qaisar, A. Subasi, K.A. Rambo, "An event driven wireless sensor network for monitoring of plants' health and larva activities", IEEE 2018, 978-1-5386-4110-1/18.

[5]. Arif Ghori, Manglesh Singh, OjasThanawala, AnupamVishwakarma, \& Prof. Ashfaque
Shaikh(2017), Smart Irrigation System using IOT, International Journal of Advanced Research in Computer and Communication Engineering(IJARCCE).

[6]. Barth R, IJsselmuiden J M M, Hemming J, van Henten E J. Optimising realism of synthetic agricultural images using cycle generative adversarial networks. Proceedings of the IEEE IROS workshop on Agricultural Robotics/Kounalakis, Tsampikos, van Evert, Frits, Ball, David Michael, Kootstra, Gert, Nalpantidis, Lazaros, Wageningen: Wageningen University \& Research, 2017; pp.18-22.

http://library.wur.nl/WebQuery/wurpubs/ 533105.

[7]. Batchelor, W.D., McClendon, R.W., Adams, D.B., Jones, J.W., 1989. Evaluation of SMARTSOY: an expert simulation system for insect pest management. Agric. Syst. 31 (1), 6781.

[8]. Biswas S K, Sinha N, Purkayastha B, Marbaniang L. Weather prediction by recurrent neural network dynamics. International Journal of Intelligent Engineering Informatics, 2014; 2(2-3): 166-180.

[9]. Chai L N, Qu Y H, Zhang L X, Liang S L, Wang $J$ D. Estimating time-series leaf area index based on recurrent nonlinear autoregressive neural networks with exogenous inputs International Journal of Remote Sensing, 2012; 33 (18): 5712-5731.

[10]. Chen S W, Shivakumar S S, Dcunha S, Das J, Okon E, Qu C, et al. Counting apples and oranges with deep learning: A data-driven approach. IEEE Robotics and Automation Letters, 2017; 2(2): 781-788.

[11]. Chen B Q, Wu Z X, Wang J K, Dong J W, Guan L M, Chen J M, et al. Spatio-temporal prediction of leaf area index of rubber plantation using $\mathrm{HJ}-1 \mathrm{~A} / 1 \mathrm{~B}$ CCD images and 
recurrent neural network. ISPRS Journal of Photogrammetry and Remote Sensing, 2015; 102: 148-160.

[12]. Christiansen P, Hansen M, Steen K, Karstoft H, Jørgensen R. Advanced sensor platform for human detection and protection in autonomous farming. In Precision Agriculture'15; Wageningen Academic Publishers: Wageningen, the Netherlands, 2015; pp.1330-1334.

[13]. Demmers T G M, Gauss S, Wathes C M, Cao Y, Parsons D J. Simultaneous monitoring and control of pig growth and ammonia emissions. IX International Livestock Environment Symposium, 2012; C-1323.

[14]. Dr. V. Balamurugan, Sujith P. S., \&MeeraGovind G.(2017), Design and Implementation of Smart Irrigation System with Uninterrupted Power Supply, International Journal of Advanced Research in Computer and Communication Engineering,Vol. 6, Special issue 4.

[15]. G A Gines, J G Bea, \& T D Palaoag (2018), Characterization of Soil Moisture Level for Rice and Maize Crops using GSM Shield and Arduino Microcontroller, IOP Conference Series: Materials Science and Engineering, Volume 325, Issue 1, pp. 012019.

[16]. Ledig C, Theis L, Huszar F, Caballero J, Cunningham A, Acosta A, et al. Photo-realistic single image super-resolution using a generative adversarial network. IEEE Conference on Computer Vision and Pattern Recognition (CVPR), Honolulu, Hawaii, USA, 2017; pp.105-114.

[17]. Lu H, Fu X, Liu C, Li L G, He Y X, Li N W. Cultivated land information extraction in UAV imagery based on deep convolutional neural network and transfer learning. Journal of Mountain Science, 2017; 14(4): 731-741.
[18]. Minh D H T, Ienco D, Gaetano R, Lalande N, Ndikumana E. Deep recurrent neural networks for winter vegetation quality mapping via multitemporal SAR Sentinel-1. IEEE Geoscience \& Remote Sensing Letters, 2017; 99: 1-5.

[19]. Ms.Swapnali B.Pawar, Prof.Priti Rajput, \&Prof. Asif Shaikh (2018), Smart Irrigation System Using IOT and Raspberry Pi, International Research Journal of Engineering and Technology (IRJET).

[20]. Muhammed ammad udin, Denis Le Jenne, Hadi M. Aggoune, Muhammed Ayaz, "UAV routing protocol for crop health management", 2018, 24th european signal processing conference (EUSIPCO).

[21]. Namin S T, Esmaeilzadeh M, Najafi M, Brown T B, Borevitz J O. Deep phenotyping: Deep learning for temporal phenotype/genotype classification. bioRxiv, 2017. doi: https://doi.org/10.1101/134205.

[22]. Palangpour P, Venayagamoorthy G K, Duffy K. Recurrent neural network based predictions of elephant migration in a South African game reserve. International Joint Conference on Neural Networks, 2006: pp.4084-4088.

[23]. Ravichandran, G., Koteshwari, R.S., 2016. Agricultural crop predictor and advisor using ANN for smartphones. IEEE 1-6.

[24]. Roach, J., Virkar, R., Drake, C., Weaver, M., 1987. An expert system for helping apple growers. Comput. Electron. Agric. 2 (2), 97108.

[25]. S NaliniDurga\& M Ramakrishna (2018), Smart Irrigation System based on soil moisture using IOT, International Research Journal of Engineering and Technology (IRJET), Volume: 05, Issue : 06.

[26]. S. Veenadhari, Dr. Bharat Misra,Dr.\& CD Singh (2014), Machine learning approach for forecasting crop yield based on climatic 
parameters, Conference : 2014 International Conference on Computer Communication and Informatics (ICCCI).

[27]. Shobha S. Kumbar, VishalPatil, MalaykumarSenapati, AnkushPatil, ShubhamSawant,\& Deepak Londhe (2018), Smart Irrigation and Farming Techniques, International Journal of advance research Ideas and Innovation in Technology,Volume-4, Issue- 2 .

[28]. Sladojevic S, Arsenovic M, Anderla A, Culibrk D, Stefanovic D. Deep neural networks based recognition of plant diseases by leaf image classification. Computational Intelligence and Neuroscience, 2016; Article ID 3289801, 11p.

[29]. Song, H., He, Y., 2005. Crop nutrition diagnosis expert system based on artificial neural networks. Third International Conference on Information Technology and Applications (ICITA'05), Sydney, NSW, 2005, 1, pp. 357362.

[30]. Srishti Rawal (2017), IOT based Smart Irrigation System, International Journal of Computer Applications.

[31]. Steen K A, Christiansen $\mathrm{P}$, Karstoft $\mathrm{H}$, Jørgensen $\mathrm{R} N$. Using deep learning to challenge safety standard for highly autonomous machines in agriculture. Journal of Imaging, 2016; 2(1): 6.

[32]. Stone, N.D., Toman, T.W., 1989. A dynamically linked expert-database system for decision support in Texas cotton production. Comput. Electron. Agric. 4 (2), 139-148.

[33]. Terteil A. A. Ali, Viraj Choksi, Dr. M. B. Potdar, "Precision agriculture monitoring system using green internet of things (G-IOT)", proceedings of the 2nd international conference on trends in electronics and informatics (ICOEI- 2018) IEEE conference record ISBN 978-1-5386-3570-4.
[34]. V. Vinoth Kumar, R.Ramasamy, S.Janarthanan, \&M. VasimBabu (2017), Implementation of IOT in smart irrigation system using Arduino Processor, International Journal of Civil Engineering and Technology (IJCIET).

[35]. Vrushal Milan Dolas\&Prof.Uday Joshi (2018), A Novel Approach for Classification of Soil and Crop Prediction, International Journal of Computer Science and Mobile Computing, Vol. 7, Issue 3.

[36]. Yalcin H. Plant phenology recognition using deep learning: 6th International Conference on Deep-Pheno. Agro-Geoinformatics, IEEE, 2017.

[37]. Yalcin H, Razavi S. Plant classification using convolutional neural networks. Fifth International Conference on AgroGeoinformatics (Agro-Geoinformatics), IEEE, 2016

[38]. Zaytar M A, El Amrani C. Sequence to sequence weather forecasting with long shortterm memory recurrent neural networks. International Journal of Computer Applications, 2016; 143(11): 7-11

\section{Cite this article as :}

Anshika Agarwal, Y. D. S. Arya, Gaurav Agarwal, Shruti Agarwal, "Detailed study of AI/ML in Smart Agriculture", International Journal of Scientific Research in Computer Science, Engineering and Information Technology (IJSRCSEIT), ISSN : 24563307, Volume 7 Issue 3, pp. 130-145, May-June 2021.

Available at

doi: https://doi.org/10.32628/CSEIT21734

Journal URL : https://ijsrcseit.com/CSEIT21734 